\title{
A Monoclonal Antibody against 6-Acetylmorphine Protects Female Mice Offspring from Adverse Behavioral Effects Induced by Prenatal Heroin Exposure
}

\author{
Anne Marte Sjursen Kvello, Jannike Mørch Andersen, Elisabeth Leere Øiestad, \\ Synne Steinsland, Audun Aase, Jørg Mørland, and Inger Lise Bogen
}

Section for Drug Abuse Research, Department of Forensic Sciences, Oslo University Hospital, Oslo, Norway (A.M.S.K., J.M.A., E.L.Ø., S.S., I.L.B.); School of Pharmacy, Faculty of Mathematics and Natural Sciences (A.M.S.K., J.M.A., E.L.Ø.), Institute of Basic Medical Sciences (I.L.B.) and Institute of Clinical Medicine (J.M.), Faculty of Medicine, University of Oslo, Oslo, Norway; and Department of Infectious Disease Immunology (A.A.) and Department of Health Data and Digitalization (J.M.), Norwegian Institute of Public Health, Oslo, Norway

Received June 19, 2018; accepted October 22, 2018

\begin{abstract}
Escalating opioid use among fertile women has increased the number of children being exposed to opioids during fetal life. Furthermore, accumulating evidence links prenatal opioid exposure, including opioid maintenance treatment, to longterm negative effects on cognition and behavior, and presses the need to explore novel treatment strategies for pregnant opioid users. The present study examined the potential of a monoclonal antibody (mAb) targeting heroin's first metabolite, 6 -acetylmorphine (6-AM), in providing fetal protection against harmful effects of prenatal heroin exposure in mice. First, we examined anti-6-AM mAb's ability to block materno-fetal transfer of active metabolites after maternal heroin administration. Next, we studied whether maternal mAb pretreatment could prevent adverse effects in neonatal and adolescent
\end{abstract}

offspring exposed to intrauterine heroin $(3 \times 1.05 \mathrm{mg} / \mathrm{kg})$. Anti-6-AM mAb pretreatment of pregnant dams profoundly reduced the distribution of active heroin metabolites to the fetal brain. Furthermore, maternal mAb administration prevented hyperactivity and drug sensitization in adolescent female offspring prenatally exposed to heroin. Our findings demonstrate that passive immunization with a 6-AM-specific antibody during pregnancy provides fetal neuroprotection against heroin metabolites, and thereby prevents persistent adverse behavioral effects in the offspring. An immunotherapeutic approach to protect the fetus against long-term effects of prenatal drug exposure has not been reported previously, and should be further explored as prophylactic treatment of pregnant heroin users susceptible to relapse.

\section{Introduction}

Opioid use among fertile women has escalated dramatically in recent years, leading to an increased number of children being exposed to opioids during pregnancy (McQueen and Murphy-Oikonen, 2016; Terplan, 2017). While the use of prescription and designer opioids is rising, especially in North America, heroin still remains the most commonly abused opioid drug worldwide (http://www.unodc.org/wdr2017). Newborns prenatally exposed to heroin or other opioids display adverse effects such as neonatal abstinence syndrome, decreased head circumference, poor fetal growth, and increased risk for certain birth defects (Broussard et al., 2011; McQueen and Murphy-Oikonen, 2016). In addition, increasing evidence links prenatal opioid exposure to long-term effects on cognition and behavior, such as learning and memory impairment,

This work was supported by the Research Council of Norway [Grant 213751]

https://doi.org/10.1124/jpet.118.251504. hyperactivity, and attention deficit hyperactivity disorder (ADHD) (Hickey et al., 1995; Ornoy et al., 1996, 2001; Sundelin Wahlsten and Sarman, 2013; Levine and Woodward, 2018). In accordance with human findings, animal studies have reported long-term behavioral deficits in adult offspring after prenatal exposure to heroin, including hyperactivity and reduced memory processing (Lasky et al., 1977; Zhu and Stadlin, 2000; Yanai et al., 2003; Wang and Han, 2009; Lu et al., 2012). Furthermore, rodent offspring exposed to intrauterine opioids show increased drug sensitization and drug self-administration, indicating alterations in the reward system, which may enhance vulnerability to drugs later in life (Castellano and Ammassari-Teule, 1984; Gagin et al., 1997; Wu et al., 2009; Timár et al., 2010; Chiang et al., 2014; Wong et al., 2014).

The recommended treatment of heroin-dependent pregnant women is opioid maintenance treatment with methadone or buprenorphine, which successfully reduces morbidity and illicit drug use (White and Lopatko, 2007; Minozzi et al.,

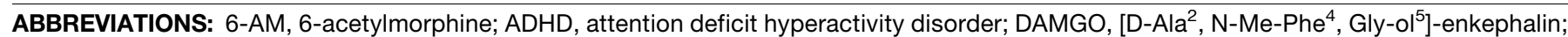
$\mathrm{E}$, embryonic day; ELISA, enzyme-linked immunosorbent assay; LC-MSMS, liquid chromatography-tandem mass spectrometry; mAb, monoclonal antibody; M3G, morphine-3-glucuronide; P, postnatal day; USV, ultrasonic vocalization. 
2013). However, as for other opioids, maternal opioid maintenance treatment has been shown to induce harmful effects in both human and animal offspring (Farid et al., 2008; Fodor et al., 2014). To avoid opioid maintenance treatment-induced insult to the developing fetus, new treatment options for pregnant heroin users should be explored. A potential novel approach is antidrug immunotherapy, which is based on specific antibodies sequestering the drug in the blood, thereby preventing drug distribution to the brain (Zalewska-Kaszubska, 2015). Antidrug immunotherapy entails active vaccination, which exploits the organism's own immune system to trigger antibody production, or passive immunization with injection of preformed monoclonal antibodies (mAbs) (Janda and Treweek, 2012).

Immunization against heroin was demonstrated as a proof of concept decades ago (Bonese et al., 1974; Killian et al., 1978), and subsequently a number of active and passive vaccines have been developed and tested against heroin effects in adult rodents (Stowe et al., 2011; Pravetoni et al., 2012; Raleigh et al., 2014; Sulima et al., 2018). We recently examined the properties of a mAb specifically targeting heroin's first metabolite, 6-acetylmorphine (6-AM) (Bogen et al., 2014; Kvello et al., 2016), which together with morphine is considered a major contributor to heroin-induced effects (Umans and Inturrisi, 1981; Andersen et al., 2009). Passive immunization with anti-6-AM mAb dose dependently reduced heroin-induced psychomotor activation and brain levels of 6-AM and morphine in adult male mice (Bogen et al., 2014; Kvello et al., 2016). While maternal immunization for fetal protection against nicotine, methamphetamine, and phencyclidine has been investigated in rats (Keyler et al., 2003, 2005; Hubbard et al., 2011a; White et al., 2014), maternal immunization against heroin has not been reported previously. Furthermore, former studies have primarily assessed materno-fetal drug distribution, whereas immunotherapeutic protection against long-term effects of prenatal drug exposure has not been explored.

In the present study, we hypothesized that anti-6-AM mAb administered to pregnant mice protects the offspring from harmful effects of intrauterine heroin exposure. To address this, we first examined the ability of the mAb to reduce transfer of active heroin metabolites to the fetus upon heroin administration to pregnant mice. Next, we assessed the efficacy of maternal mAb administration to counteract adverse effects in neonatal and adolescent offspring induced by repeated prenatal heroin exposure. Through these experiments, we aimed to demonstrate that maternal anti-6-AM $\mathrm{mAb}$ pretreatment could prevent persistent heroin-induced changes in the developing fetal brain.

\section{Materials and Methods}

\section{Animals}

Time-mated female C57BL/6J mice arriving on embryonic day (E) 8 (E8; experiment II) or 14 (E14; experiment I) (10-12 weeks old, 20-33 g; Janvier Laboratories, Saint-Berthevin, France) were housed from two to four per cage in the animal facility at the Norwegian Institute of Public Health (Oslo, Norway). The pregnant females were acclimatized for at least 3 days prior to the experiments. In experiment II, maternal weight was registered on E11, E14, and E17. From E18, pregnant females were housed individually, and disturbance to the females and their offspring was kept to a minimum during the first two postnatal weeks. Temperature, humidity, and light were regulated $\left(22 \pm 1{ }^{\circ} \mathrm{C}, 50 \% \pm 10 \%\right.$ humidity, light period $7 \mathrm{AM}$ to $\left.7 \mathrm{PM}\right)$, and commercial mouse pellets and water were available ad libitum. The behavioral experiments were conducted during the light cycle of the day under dimmed lighting. All experimental protocols were approved by the Norwegian Animal Research Authority (Norwegian Food Safety Authority, Oslo, Norway).

\section{Materials}

Heroin-HCl (421.91 mol. wt.) was purchased from Lipomed AG (Arlesheim, Switzerland) and dissolved in 0.9\% saline. Anti-6-AM mAb (human IgG1) was produced in stable, transfected Chinese hamster ovary cells (clone 214) provided by Affitech Research AS (Oslo, Norway), as described in more detail previously (Moghaddam et al., 2003). In short, the Chinese hamster ovary cells were grown in HyClone SFM4CHO-Utility Medium (VWR, Oslo, Norway) in Integra CELLine CL-1000 in vitro units (BioNordika, Oslo, Norway). The supernatants were harvested twice a week and fractionated by gel filtration on a HiLoad Superdex 200 column (Pharmacia Fine Chemicals, Uppsala, Sweden). The IgG peaks were collected and concentrated by Amicon Ultra-15 centrifugal filters and subsequently passed through a Pierce High Capacity Endotoxin Removal Resin column (ThermoFisher, Oslo, Norway) to remove endotoxins. Finally, the mAb was diluted in $0.9 \%$ saline and stored at $-80^{\circ} \mathrm{C}$. The properties of the anti-6-AM mAb have been described previously (Bogen et al., 2014; Kvello et al., 2016). Opioid doses were chosen based on previous pharmacokinetic and behavioral studies in mice (Andersen et al., 2009; Bogen et al., 2014; Kvello et al., 2016), while mAb doses were chosen based on opioid:mAb ratio experiments reported in Kvello et al. (2016).

\section{Experiment I. The Effect of Anti-6-AM mAb Pretreatment on Maternal Drug Response and Materno-Fetal Distribution of Heroin Metabolites}

The Effect of mAb Pretreatment on Heroin-Induced Locomotor Activity in Pregnant Dams (E12). Drug-naive pregnant mice (E11) were randomly assigned to three different treatment groups: saline, heroin, and $\mathrm{mAb}+$ heroin. The heroin group $(n=10)$ received saline pretreatment $(0.9 \%$, s.c.) on E11, followed by heroin injection $(2.5 \mu \mathrm{mol} / \mathrm{kg} ; 1.05 \mathrm{mg} / \mathrm{kg}$, s.c.) on E12, 24 hours after the pretreatment. The $\mathrm{mAb}+$ heroin group $(n=12)$ received anti-6-AM $\mathrm{mAb}$ pretreatment $(50 \mathrm{mg} / \mathrm{kg}$, s.c.) on E11 followed by heroin injection $(2.5 \mu \mathrm{mol} / \mathrm{kg}$, s.c.) on E12. The saline group $(n=11)$ received saline injections $(0.9 \%, 10 \mathrm{ml} / \mathrm{kg}$, s.c.) on both $\mathrm{E} 11$ and E12.

The dams were habituated individually in activity chambers for 60 minutes prior to the injection on E12. Immediately after injection ( $t=0$ minutes), each mouse was quickly returned to its respective activity chamber for recording of locomotor activity for 90 minutes. The locomotor activity was recorded in Plexiglas chambers $(20 \times$ $20 \mathrm{~cm}$ ) using a Versamax optical animal activity monitoring system (AccuScan Instruments Inc., Columbus, $\mathrm{OH}$ ) as previously described (Andersen et al., 2009).

Blood and Brain Sampling from Pregnant Dams and Fetuses for Opioid and Antibody Concentration Analyses. Drug-naive pregnant mice (E17) were randomly assigned to two groups: heroin and $\mathrm{mAb}+$ heroin. The heroin group $(n=10)$ received saline pretreatment $(0.9 \%$, s.c.) on E17, followed by heroin injection $(2.5 \mu \mathrm{mol} / \mathrm{kg}$, s.c. $) 24$ hours later on $\mathrm{E} 18$. The $\mathrm{mAb}+\operatorname{heroin}$ group $(n=$ 10) received anti-6-AM mAb pretreatment (50 mg/kg, s.c.) on E17, followed by heroin injection $(2.5 \mu \mathrm{mol} / \mathrm{kg}$, s.c.) on E18. Blood and brain samples were collected from pregnant dams and fetuses 10 and 25 minutes after heroin injection. Blood sampling was performed as follows: pregnant dams were anesthetized with isoflurane 2 to 3 minutes prior to blood sampling by heart puncture using a syringe needle prefilled with $80 \mu \mathrm{l}$ heparin $(100 \mathrm{IU} / \mathrm{ml})$. Blood samples $(100 \mu \mathrm{l})$ for opioid analysis were transferred to $5 \mathrm{ml}$ tubes containing $100 \mu \mathrm{l}$ icecold ammonium formate buffer ( $5 \mathrm{mM}, \mathrm{pH} 3.1)$ with sodium fluoride 
$(4 \mathrm{mg} / \mathrm{ml})$ and quickly frozen in liquid nitrogen. Immediately following blood sampling from the dam, the embryonic sacs containing the fetuses were opened and fetuses were immediately decapitated. Trunk blood from three fetuses per litter was collected using a syringe needle prefilled with $20 \mu \mathrm{l}$ heparin $(100 \mathrm{IU} / \mathrm{ml})$ and pooled into one Eppendorf tube. Fifty microliters of the pooled fetal blood was transferred to $5 \mathrm{ml}$ tubes containing $50 \mu \mathrm{l}$ ice-cold ammonium formate buffer $(5 \mathrm{mM}, \mathrm{pH}$ 3.1 ) with sodium fluoride $(4 \mathrm{mg} / \mathrm{ml})$. The blood samples were stored at $-80^{\circ} \mathrm{C}$ until opioid analysis by liquid chromatography-tandem mass spectrometry (LC-MSMS) performed within 24 hours. The remaining blood was immediately frozen in liquid nitrogen and stored at $-80^{\circ} \mathrm{C}$ until antibody IgG1 quantification by enzymelinked immunosorbent assay (ELISA). Brain sampling was performed as follows: after blood sampling and cervical dislocation of the dams, the cerebrum was quickly removed, washed in ice-cold $0.9 \%$ saline solution, and blotted on filter paper. Brain tissue was homogenized ( $4 \mathrm{ml} / \mathrm{g}$ tissue) in ice-cold ammonium formate buffer $(5 \mathrm{mM}, \mathrm{pH} 3.1)$ containing sodium fluoride $(4 \mathrm{mg} / \mathrm{ml})$. Duplicates of $200 \mu \mathrm{l}$ brain homogenate were transferred to $5 \mathrm{ml}$ plastic tubes and immediately frozen in liquid nitrogen. Fetal brains were collected individually from three fetuses per litter, immediately after decapitation. Each brain was homogenized in $300 \mu \mathrm{l}$ ice-cold ammonium formate buffer $(5 \mathrm{mM}$, $\mathrm{pH}$ 3.1) containing sodium fluoride $(4 \mathrm{mg} / \mathrm{ml})$. Duplicates of $100 \mu \mathrm{l}$ brain homogenate were transferred to $5 \mathrm{ml}$ plastic tubes and quickly frozen in liquid nitrogen. Brain homogenates were stored at $-80^{\circ} \mathrm{C}$ until opioid analysis by LC-MSMS performed within 24 hours.

Opioid Analysis in Blood and Brain Tissue. Total concentrations (both free and $\mathrm{mAb}$ bound) of the heroin metabolites 6-AM, morphine, and morphine-3-glucuronide (M3G) were quantified by a LC-MSMS method previously described in detail (Karinen et al., 2009). The limits of detection in brain tissue were $0.003 \mathrm{nmol} / \mathrm{g}$ for $6-\mathrm{AM}$ and $0.005 \mathrm{nmol} / \mathrm{g}$ for morphine. The limits of detection in blood were $0.0008,0.0014$, and $0.013 \mathrm{nmol} / \mathrm{ml}$ for 6-AM, morphine, and M3G, respectively. Data acquisition, peak integration, and quantification of samples were performed using MassLynx 4.0 SCN509 software (Waters Corp., Milford, MA).

Antibody Quantification in Blood. Blood samples from anti6-AM mAb pretreated dams $(n=5)$ and fetuses $(n=8)$ were diluted in distilled water and analyzed for human IgG1 using a NOVEX ELISA kit (Thermo Fisher Scientific Inc., Waltham, MA). Absorbance was measured $(450 \mathrm{~nm})$ using an ELx808 Absorbance Microplate Reader (BIO-TEK Instruments Inc., Winooski, VT).

\section{Experiment II. Maternal Anti-6-AM mAb Pretreatment as Protection against Prenatal Heroin Exposure in Neonatal and Adolescent Offspring}

Prenatal Exposure to Heroin (E11-E18). Drug-naive pregnant mice (E11) were randomly assigned to three groups: saline, heroin, and $\mathrm{mAb}+$ heroin. Mice in the saline group $(n=11)$ received s.c. saline injections $(0.9 \%)$ on E11, E12, E14, E15, E17, and E18. Mice in the heroin group $(n=10)$ received s.c. saline injections on E11, E14, and E17 and single s.c. heroin injections $(2.5 \mu \mathrm{mol} / \mathrm{kg})$ on E12, E15, and E18. Mice in the $\mathrm{mAb}+$ heroin group $(n=12)$ received s.c. $\mathrm{mAb}$ injections on E11 (50 mg/kg), E14 (10 mg/kg), and E17 $(10 \mathrm{mg} / \mathrm{kg})$, and single s.c. heroin injections $(2.5 \mu \mathrm{mol} / \mathrm{kg})$ on E12, E15, and E18. An overview of the treatment groups, timeline for injections during pregnancy, and experimental procedures performed in offspring are described in Fig. 3.

Ultrasonic Vocalization in Neonatal Mice. Ultrasonic vocalization (USV) was measured in individual offspring $(n=26-34$ from each treatment group) on postnatal day (P) 1 (i.e., P1). The pups were weighed and isolated from their mother and littermates for 15-20 minutes by placing them in a separate cage with regulated heating. The recordings of USV were conducted in a separate room, where each pup was placed individually in a Plexiglas cage with regulated heating and an ultrasound microphone (UltraVox 3.0; Noldus Information Technology, Wageningen, The Netherlands) was attached $15 \mathrm{~cm}$ above the animal. Vocalizations in the $50-100 \mathrm{kHz}$ range were recorded for 6 minutes using UltraVox XT 3.0 software (Noldus Information Technology). After recording, the pup was immediately returned to its home cage.

Sampling of Blood and Brain Tissue from Neonatal Mice. Three pups per litter were sacrificed by decapitation on P1. Immediately after decapitation, trunk blood was collected from individual mice using a syringe prefilled with $10 \mu \mathrm{l}$ heparin $(100 \mathrm{IU} / \mathrm{ml})$. Whole blood samples were quickly frozen in liquid nitrogen and stored at $-80^{\circ} \mathrm{C}$ until quantification of corticosterone. Immediately following blood sampling, the brains were collected and frozen in liquid nitrogen. Brain samples were stored at $-80^{\circ} \mathrm{C}$ until opioid receptor binding studies.

Opioid Receptor Binding. Brains collected from mice on P1 $(n=$ 9-15 for each treatment group) were weighed, thawed, and homogenized (glass-Teflon, $2000 \mathrm{rpm}, 40$ seconds) in ice-cold incubation buffer $(20 \mathrm{ml} / \mathrm{g}, \mathrm{pH}$ 7.4) containing $50 \mathrm{mM}$ Tris-HCl, $120 \mathrm{mM} \mathrm{NaCl}, 5 \mathrm{mM}$ $\mathrm{KCl}, 2 \mathrm{mM} \mathrm{CaCl}_{2}$, and $0.5 \mathrm{mM} \mathrm{MgCl}_{2}$. Whole brain homogenate was centrifuged for 30 minutes $\left(30,000 \mathrm{~g}, 4^{\circ} \mathrm{C}\right)$ and the supernatant discarded. The pellet was resuspended in incubation buffer and incubated for 30 minutes at $37^{\circ} \mathrm{C}$ to remove endogenous opioids. The suspension was centrifuged for 30 minutes $\left(30,000 \mathrm{~g}, 4^{\circ} \mathrm{C}\right)$ and the resulting pellet was resuspended in incubation buffer. Samples were aliquoted and stored at $-80^{\circ} \mathrm{C}$

Brain homogenate samples (duplicates) were preincubated (10 minutes, $\left.25^{\circ} \mathrm{C}\right)$ before incubation for 60 minutes $\left(25^{\circ} \mathrm{C}\right)$ with $2 \mathrm{nM}\left[{ }^{3} \mathrm{H}\right]$ DAMGO ([D-Ala ${ }^{2}, \mathrm{~N}-\mathrm{Me}_{\mathrm{Phe}}{ }^{4}, \mathrm{Gly}^{\left.-\mathrm{ol}^{5}\right]}{ }^{5}$-Enkephalin; PerkinElmer, Oslo, Norway) (final volume $200 \mu \mathrm{l}$ ). Nonspecific binding was determined by adding $10 \mu \mathrm{M}$ naloxone to parallel samples. The binding reaction was terminated by dilution with ice-cold $50 \mathrm{mM}$ Tris- $\mathrm{HCl}(\mathrm{pH}$ 7.4 ) and rapid filtration through $\mathrm{GF} / \mathrm{B}$ glass microfiber filters $(25 \mathrm{~mm}$; VWR) pretreated for 60 minutes in $0.5 \%$ polyethyleneimine solution. The filters were washed three times, and $4 \mathrm{ml}$ UltimaGold was added to each filter before radioactivity counting in a liquid scintillation analyzer (Tri-Carb 2810TR; PerkinElmer). Specific receptor binding was calculated as total minus nonspecific binding, and then converted to the amount of $\left[{ }^{3} \mathrm{H}\right] \mathrm{DAMGO}$ bound per milligram tissue protein (femtomoles per milligram). Protein content was measured as previously described (Lowry et al., 1951).

Corticosterone Quantification in Blood from Neonatal Mice. Blood samples from P1 offspring ( $n=9-15$ for each treatment group) were thawed and diluted in assay sample buffer and analyzed for mouse corticosterone using a competitive ELISA kit (Thermo Fisher Scientific, Inc.). Absorbance was measured (450 nm) using an ELx808 Absorbance Microplate Reader (BIO-TEK Instruments Inc.).

Locomotor Activity in Adolescent Mice. Heroin-induced locomotor activity in adolescent mice prenatally exposed to saline $(n=$ 8 males; $n=11$ females $)$, heroin ( $n=8$ males; $n=9$ females $)$, or mAb + heroin ( $n=12$ males; $n=14$ females), was measured on P28 according to the procedure described in experiment I. Locomotor activity during the habituation phase (60 minutes) was recorded to measure the animals' basal activity in a novel environment. Immediately after habituation, each mouse was given a heroin injection $(1.5 \mu \mathrm{mol} / \mathrm{kg}$, equivalent to $0.7 \mathrm{mg} / \mathrm{kg}$, s.c., $t=0$ minutes), and quickly returned to its respective activity chamber where locomotor activity was recorded for 20 minutes.

Blood and Brain Sampling from Adolescent Mice for Opioid and Antibody Quantification. Immediately after the locomotor activity test, the mice were transferred from the activity chambers to a separate room and sacrificed for sampling of brain tissue for opioid quantification and blood sampling for human IgG1 quantification. Blood sampling was performed as follows: mice $(n=7)$ from the $\mathrm{mAb}+$ heroin group were anesthetized with isoflurane, and blood was sampled by heart puncture 25 minutes after heroin injection using a syringe needle prefilled with $80 \mu \mathrm{l}$ heparin $(100 \mathrm{IU} / \mathrm{ml})$. Whole blood samples were quickly frozen in liquid nitrogen and stored at $-80^{\circ} \mathrm{C}$ until antibody quantification by ELISA, performed as described in experiment I. Brain sampling was performed as follows: after cervical 
dislocation, the cerebrum was quickly removed from all animals included in the locomotor activity test (P28), washed in ice-cold 0.9\% saline solution, and blotted on filter paper. The brain tissue was homogenized and analyzed for heroin metabolites as described in experiment I.

Data and Statistical Analysis. Data are presented as mean + S.E.M. unless stated otherwise. For comparison between two groups, the Student's $t$ test was used. One-way analysis of variance was performed for comparison of the three treatment groups (saline, heroin, and mAb + heroin) with a significant $F$ value followed by Tukey's post hoc test. Values of $P<0.05$ were considered statistically significant. Statistical tests were performed using SPSS version 23 (SPSS Inc., Chicago, IL). USV data were analyzed using UltraVox XT 3.0 software (Noldus Information Technology). The figures and tables were generated using GraphPad Prism version 7 (GraphPad Software, Inc., San Diego, CA).

\section{Results}

\section{Experiment I. The Effect of Anti-6-AM mAb Pretreatment on Maternal Drug Response and Materno-Fetal Distribution of Heroin Metabolites}

Anti-6-AM mAb Pretreatment Reduced Heroin-Induced Locomotor Activity in Pregnant Mice. We have previously reported that heroin induces locomotor activity in a dose-dependent manner in male mice (Andersen et al., 2009), and that this response can be inhibited by anti6-AM mAb pretreatment (Bogen et al., 2014; Kvello et al., 2016). Here, we tested the effect of mAb pretreatment on heroin-induced locomotor activity in pregnant mice on E12. A single heroin injection caused a rapid increase in locomotor activity, reaching $E_{\max }$ after 10 minutes $(2646 \pm 265 \mathrm{~cm}$ per 5 minutes, Fig. 1A). Pregnant mice pretreated with $\mathrm{mAb}$ displayed a significant decrease in heroin-induced locomotor activity $(P<0.05$ at $10-55$ minutes, Fig. $1 \mathrm{~A})$, with a $62 \%$ reduction in total run distance compared with mice in the heroin group $(P<0.05$, Fig. 1B). There was no difference between groups in baseline locomotor activity during habituation, and saline injection did not induce changes in locomotor activity (Fig. 1). Locomotor activity testing was initially planned also on E15 and E18; however, preliminary experiments revealed large individual differences in the animals' capability to engage in running activity at this stage of pregnancy.

Maternal Anti-6-AM mAb Pretreatment Decreased the Transfer of Active Heroin Metabolites to Fetal Blood and Brain. Pregnant mice were pretreated with $\mathrm{mAb}$ or saline 24 hours before a single heroin injection on E18 $(2.5 \mu \mathrm{mol} / \mathrm{kg}$, corresponding to $1.05 \mathrm{mg} / \mathrm{kg}$ ). The total concentration (free and $\mathrm{mAb}$ bound) of the heroin metabolites 6-AM, morphine, and M3G were measured in maternal and fetal blood and brain samples 10 and 25 minutes after heroin injection to dams. Heroin was not quantified since it is rapidly converted to 6-AM and becomes undetectable both in blood and brain within 10 minutes after injection in mice (Andersen et al., 2009; Kvello et al., 2016). The fetal blood concentration of 6-AM after heroin injection to dams was low compared with maternal blood concentrations (Fig. 2, A and D), while morphine concentrations were within the same range (Fig. 2, B and E). Essentially no M3G was detected in the fetus (Fig. 2F), possibly explained by the low levels of the enzyme Uridine 5 '-diphosphoglucuronosyltransferase (UGT) prior to birth (Fyffe and Dutton, 1975), which may contribute to poor fetal elimination of morphine. Maternal mAb pretreatment did not affect either maternal or fetal blood 6-AM or M3G concentrations. Blood morphine concentrations in mAb-pretreated mice were reduced compared with the heroin group, as observed at both 10 and 25 minutes in maternal blood and at 10 minutes in fetal blood $(P<0.05$, Fig. $2, \mathrm{~B}$ and $\mathrm{E})$.

After heroin injection to dams, the 6-AM concentration in fetal brain was $31 \%-40 \%$ of the levels measured in maternal brain (Fig. 2, G and I), while morphine concentrations were $45 \%$ (10 minutes) and $129 \%$ (25 minutes) of maternal brain concentrations (Fig. 2, $\mathrm{H}$ and J). Fetuses from dams pretreated with mAb had brain 6 -AM levels reduced by $55 \%$ and $89 \%$ at 10 and 25 minutes after heroin injection, respectively, compared with fetuses in the heroin group $(P<0.001$, Fig. 2I). $\mathrm{mAb}$ pretreatment also reduced fetal brain morphine concentrations by $92 \%$ (10 minutes) and $37 \%$ (25 minutes) $(P<0.05$, Fig. 2J). Compared with brain 6-AM levels measured in dams from the heroin group, $\mathrm{mAb}$ pretreatment reduced maternal brain 6 -AM levels by $48 \%$ and $71 \%$ at 10 and 25 minutes after heroin injection, respectively $(P<0.05$, Fig. $2 \mathrm{G})$, and brain morphine levels by $46 \%$ at 10 minutes and $51 \%$ at 25 minutes $(P<0.05$, Fig. $2 \mathrm{H})$. M3G was not detected in either maternal or fetal brain tissue.

The Anti-6-AM mAb Levels in Fetal Blood Were OneFourth of the Levels in Maternal Blood. The anti-6-AM $\mathrm{mAb}$ employed in the current study belongs to the human IgG1 subclass and was measured in maternal and fetal blood on E18, 24 hours after mAb injection. The dams had an average blood concentration of $303 \pm 8 \mu \mathrm{g} / \mathrm{ml}$, while
A
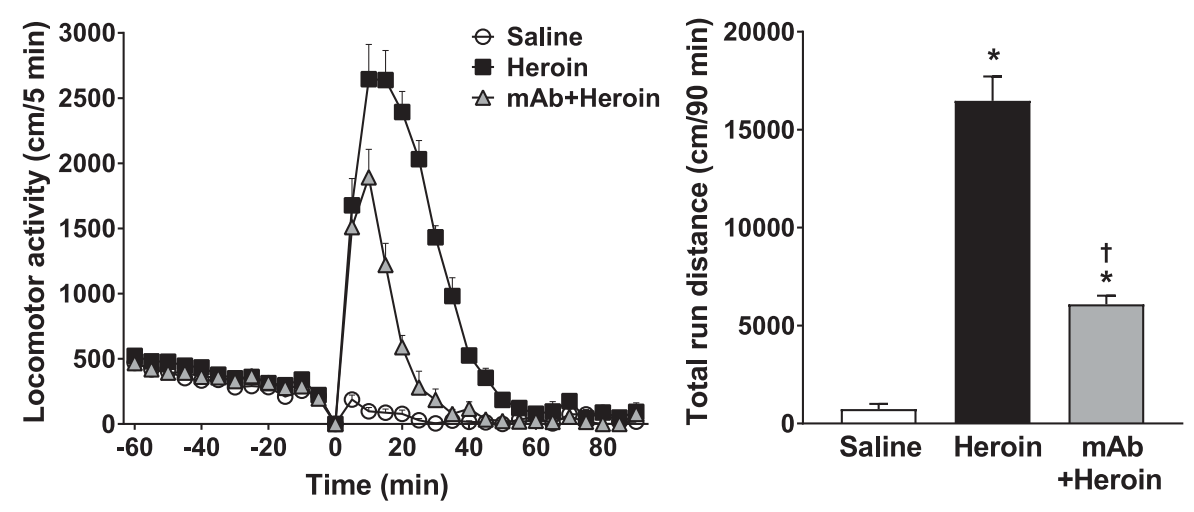

Fig. 1. Heroin-induced $(2.5 \mu \mathrm{mol} / \mathrm{kg}$, s.c. $)$ locomotor activity in pregnant mice (E12) 24 hours after pretreatment with saline or anti-6-AM $\mathrm{mAb}(50 \mathrm{mg} / \mathrm{kg}$, s.c.). Mice receiving only saline injections were included for control. The dams were habituated in the activity chambers 60 minutes prior to heroin or saline injection $(t=0)$. (A) Average locomotor activity (cm/5-minute bin), $n=$ 10-12 (except $t=25-90$ minutes, $n=4-5$ ). (B) Total run distance $(\mathrm{cm} / 90$ minutes) $(n=4-5)$. Values are expressed as mean + S.E.M., $* P<0.05$ against saline, $\dagger P<0.05$ against heroin, one-way analysis of variance with Tukey's post hoc test. 


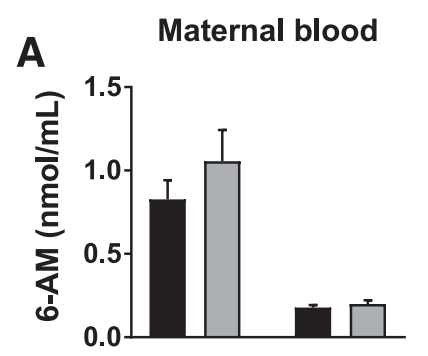

B
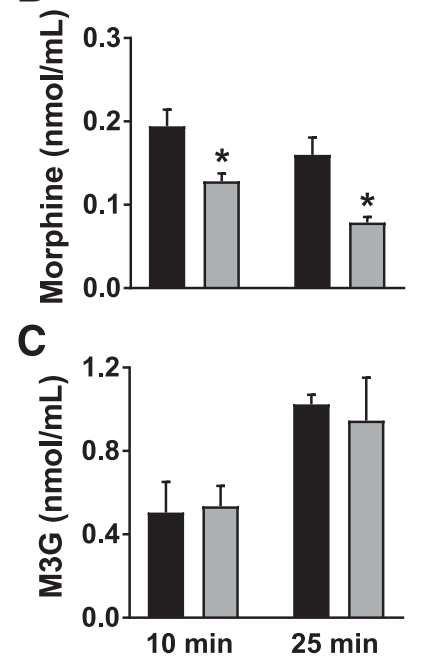

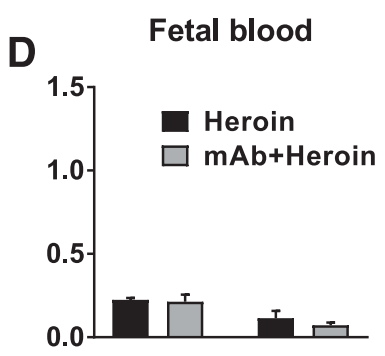

E

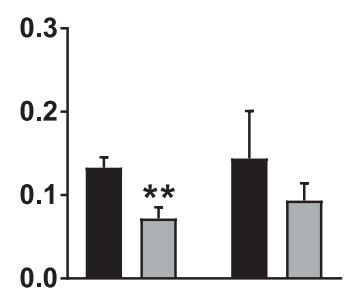

$\mathbf{F}$

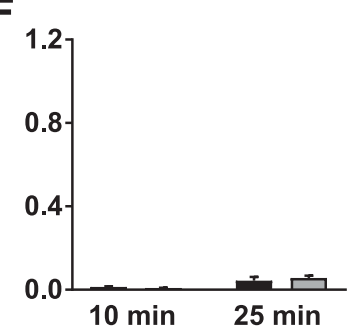

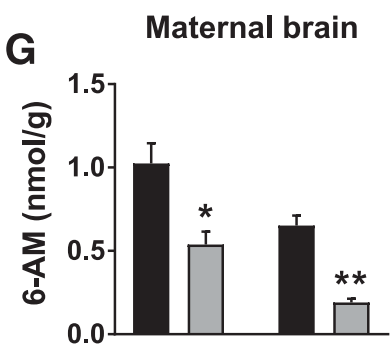

$\mathbf{H}$

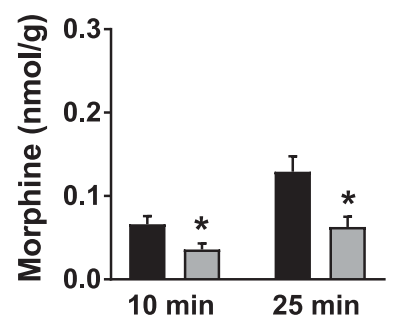

Time after heroin injection $(2.5 \mu \mathrm{mol} / \mathrm{kg})$

Time after heroin injection $(2.5 \mu \mathrm{mol} / \mathrm{kg})$

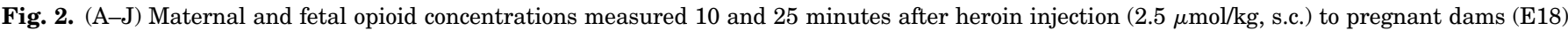

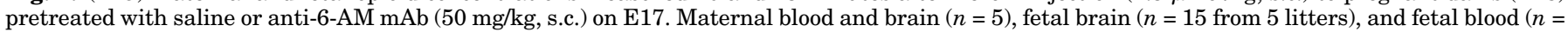
$5-8$, each blood sample pooled from three fetuses). Values are mean + S.E.M., $* P<0.05 ; * * P<0.01 ; * * * P<0.005$, Student's $t$ test.

$70 \pm 5 \mu \mathrm{g} / \mathrm{ml}$ was detected in fetal blood, comprising $23 \%$ of the IgG1 level detected in the dams.

\section{Experiment II. Maternal Anti-6-AM mAb Pretreatment as Protection against Adverse Effects of Prenatal Heroin Exposure in Neonatal and Adolescent Offspring}

The results from experiment I revealed that maternal anti6-AM mAb pretreatment reduced the distribution of active heroin metabolites to the fetal brain. In a second set of experiments, we therefore examined the effects of maternal $\mathrm{mAb}$ treatment on the outcome in neonatal and adolescent offspring after intermittent prenatal exposure to heroin. Pregnant mice were administered three single injections of heroin with a 3 -day interval during late gestation $(2.5 \mu \mathrm{mol} / \mathrm{kg}$ on E12, E15, and E18), with or without mAb pretreatment, and the effects were examined in neonatal pups (P1) and adolescent mice (P28) (see the outline in Fig. 3).

Maternal Weight Gain, Neonatal Weight, and Litter Size Were Not Affected by Heroin or Anti-6-AM mAb Pretreatment during Pregnancy. We measured maternal weight gain during pregnancy, average neonatal weight (P1), and litter size after prenatal exposure to saline, heroin, or $\mathrm{mAb}+$ heroin, and found no significant differences between the treatment groups (Table 1).

Neonatal Offspring Prenatally Exposed to Heroin Did Not Show Significant Withdrawal Symptoms. Neonatal offspring born to opioid-exposed mothers commonly

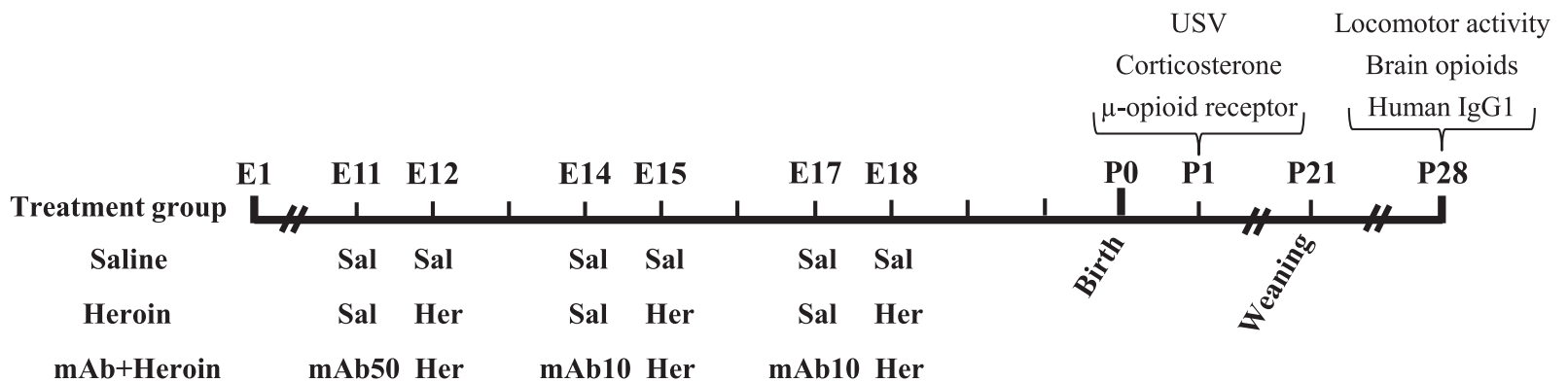

Fig. 3. Timeline for injections in pregnant dams and experiments in offspring (experiment II). Her, heroin; mAb10/50, anti-6-AM mAb 10 or $50 \mathrm{mg} / \mathrm{kg}$; Sal, saline. 
TABLE 1

Average weight gain in pregnant dams from embryonic days 11-17, litter size and pup weight on postnatal day 1

\begin{tabular}{lccc}
\hline Treatment & $\begin{array}{c}\text { Weight Gain in Dams } \\
(\text { E11-17) }\end{array}$ & Litter Size $^{a}$ & ${\text { Pup Weight }(\mathrm{P} 1)^{b}}^{b}$ \\
\hline & $(\mathrm{g})$ & $(\mathrm{n})$ & $(\mathrm{g})$ \\
Saline & $7.99 \pm 0.35$ & $6.36 \pm 0.39$ & $1.32 \pm 0.02$ \\
Heroin & $8.26 \pm 0.46$ & $6.10 \pm 0.38$ & $1.30 \pm 0.02$ \\
mAb + heroin & $8.09 \pm 0.29$ & $6.50 \pm 0.34$ & $1.32 \pm 0.02$ \\
\hline
\end{tabular}

${ }^{a} n=10-12$.

${ }_{n} n=26-46$.

show withdrawal symptoms, which can be measured as increased USV or elevated levels of stress hormones in rodents (Neal and Sparber, 1986; Barr et al., 2011). In addition, altered $\mu$-opioid receptor density in neonatal rodent brain has been reported after prenatal opioid exposure (Tempel et al., 1988; Bhat et al., 2006). We measured USV, blood corticosterone concentration, and whole brain $\mu$-opioid receptor expression in 1-day-old pups prenatally exposed to saline, heroin, or mAb + heroin, and found no significant differences between the treatment groups (Fig. 4).

Maternal Anti-6-AM mAb Pretreatment Protects against Heroin-Induced Locomotor Sensitization in Adolescent Females Prenatally Exposed to Heroin. To determine whether exposure to heroin during pregnancy could induce a sensitized drug response in adolescent offspring, and whether maternal mAb pretreatment could protect from this effect, adolescent mice were tested for heroin-induced locomotor activity on P28. Both males and females from all treatment groups displayed a marked increase in locomotor activity after a single injection of heroin $(1.5 \mu \mathrm{mol} / \mathrm{kg}$, Fig. 5 , A and B). The total run distance in female offspring prenatally exposed to heroin was doubled compared with females prenatally exposed to saline $(P<0.05$, Fig. 5B). This heroin-induced locomotor sensitization was absent in females from $\mathrm{mAb}$ pretreated mothers, and their locomotor activity was reduced by $34 \%$ ( $P=0.06)$ compared with female offspring in the heroin group (Fig. 5B). Male adolescent offspring prenatally exposed to heroin did not express a sensitized heroin-induced behavioral response, and no differences in locomotor activity were found between the male treatment groups (Fig. 5, D and E).

To examine whether the changes in behavioral response could be explained by differences in brain opioid levels, brain tissue was collected immediately after the locomotor activity test and analyzed for the heroin metabolites 6-AM and morphine. Brain opioid concentrations were within the same range in females and males from all treatment groups (Fig. 5, C and F); although a slight nonsignificant tendency of decreased levels was observed in females from the mAb + heroin group (Fig. 5C). Remaining anti-6-AM mAb was therefore assessed in blood from adolescent mice prenatally exposed to $\mathrm{mAb}$, and negligible levels of human IgG1 (5.5 \pm $1.0 \mu \mathrm{g} / \mathrm{ml}$ ) were detected. This is in accordance with the mAb's estimated biologic half-life of 8 to 9 days in mice (Bogen et al., 2014).

Maternal Anti-6-AM mAb Pretreatment Protects against Hyperactivity in Adolescent Females Prenatally Exposed to Heroin. Baseline locomotor activity in a novel environment was assessed prior to testing of drug-induced psychomotor activity in adolescent mice. The total activity recorded in adolescent females prenatally exposed to heroin was increased by $31 \%$ compared with females prenatally exposed to saline $(P<0.01$, Fig. $6 \mathrm{~A})$. The locomotor activity of female offspring exposed to $\mathrm{mAb}+$ heroin was not significantly different from either the saline controls or the heroin-exposed group. For male offspring, no differences in activity upon novelty were observed between groups (Fig. 6B).

\section{Discussion}

Our findings provide evidence that passive immunization with a monoclonal antibody during pregnancy may serve as a useful approach to protect the developing fetus from adverse heroin effects. Maternal pretreatment with anti-6-AM mAb markedly reduced the distribution of active heroin metabolites to the fetal brain upon heroin administration to pregnant mice. Furthermore, maternal mAb administration prevented adverse behavioral effects in female adolescent mice induced by intrauterine heroin exposure, suggesting efficient protection against persistent changes in the fetal brain. To our knowledge, the present study is the first to demonstrate that $\mathrm{mAb}$ pretreatment during pregnancy mediates offspring protection from long-term effects caused by prenatal drug exposure.

Lipophilic drugs such as heroin and its metabolites can easily transverse the placental barrier and distribute to fetal tissues upon maternal drug administration (Hartvig et al., 1989; Pichini et al., 2005). Heroin is considered a prodrug with
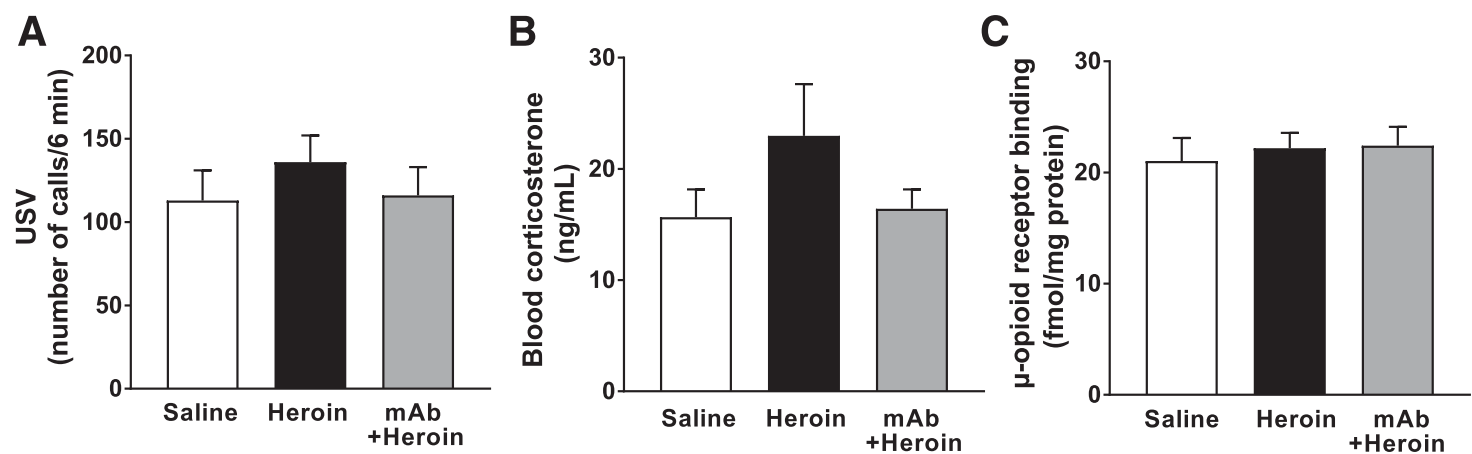

Fig. 4. Neonatal outcome in offspring (P1) prenatally exposed to saline, heroin, or mAb + heroin. (A) USVs recorded for 6 minutes, $n=26-34$ from 10 to 12 litters. (B) Blood corticosterone (nanograms per milliliter), $n=9-15$ from $n=4$ to 5 litters. (C) Brain $\mu$-opioid receptor binding by $\left[{ }^{3} \mathrm{H}\right] \mathrm{DAMGO}$ (femtomoles per milligram protein), $n=9-15$ from $n=4$ to 5 litters. Values are mean + S.E.M. 


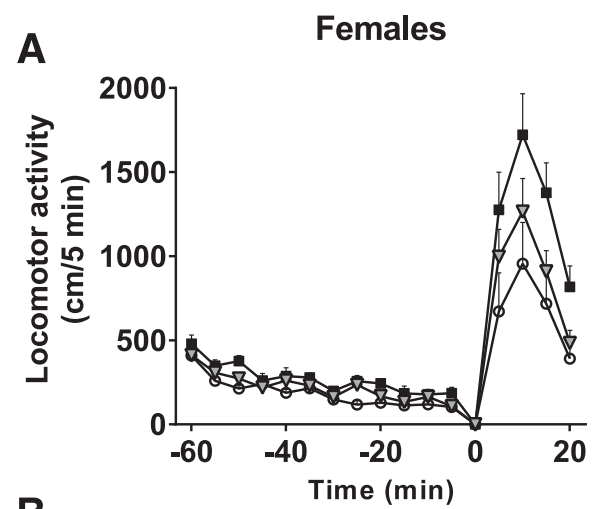

B

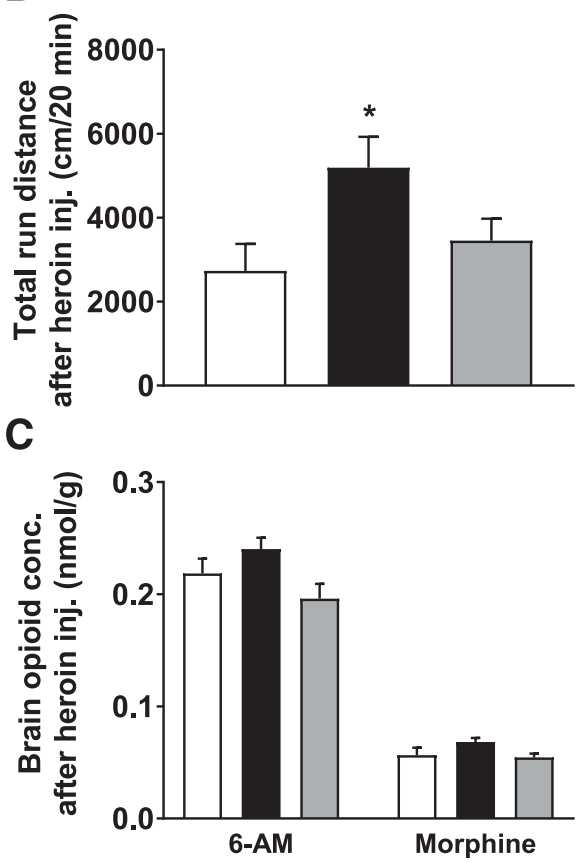

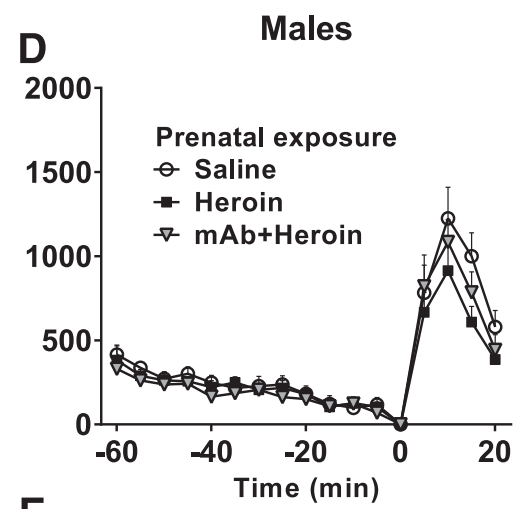

E
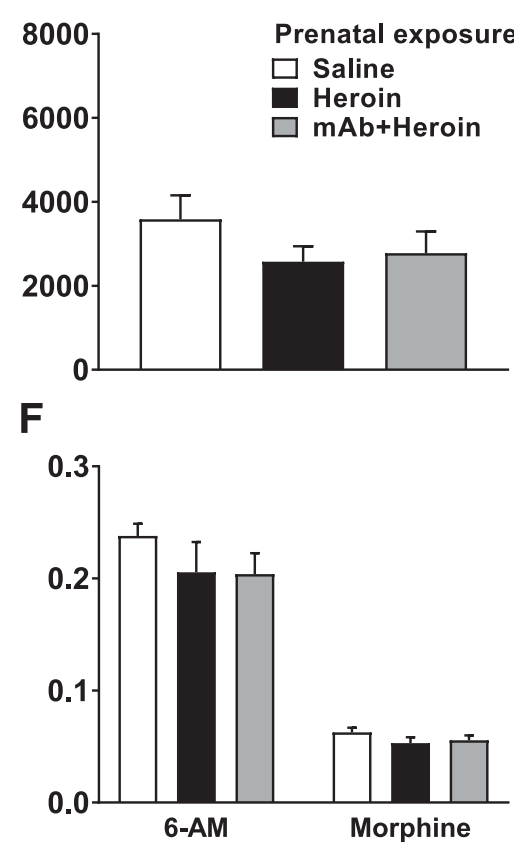

Fig. 5. Behavioral effects of prenatal exposure to saline, heroin, or $\mathrm{mAb}+$ heroin in female and male adolescent offspring (P28). (A and D) Heroin-induced (1.5 $\mu \mathrm{mol} / \mathrm{kg}$, s.c.) locomotor activity ( $\mathrm{cm} / 5$ minutes) during habituation ( $t=-60-0$ minutes), and after heroin injection ( $t=0-20$ minutes). (B and $\mathrm{E})$ Total run distance $(\mathrm{cm} / 20$ minutes) after heroin injection. (C and $\mathrm{F})$ Brain opioid concentrations measured 25 minutes after heroin injection. $n=8-14$ for locomotor activity studies; $n=5-9$ for opioid quantification. Values are mean + S.E.M., ${ }^{*} P<0.05$ against saline, one-way analysis of variance with Tukey's post hoc test. effects mediated mainly by the metabolites 6-AM and morphine. Therefore, we hypothesized that administration of a $\mathrm{mAb}$ specifically targeting $6-\mathrm{AM}$ to pregnant mice would protect the fetus from harmful heroin effects by inhibiting transfer of active heroin metabolites to the fetal brain. Indeed, the anti-6-AM mAb significantly reduced fetal 6-AM brain levels by up to $89 \%$. Although the anti-6-AM mAb does not bind morphine, fetal brain levels of morphine were also reduced, indicating indirect fetal neuroprotection against morphine effects as well. In previous studies using immunotherapy against heroin, we and others have shown that sequestration of heroin's first metabolite, 6-AM, is crucial to prevent heroin-induced effects in adult rodents (Bogen et al., 2014; Raleigh et al., 2014; Kvello et al., 2016). Our current findings demonstrate that maternal anti-6-AM mAb administration provides efficient fetal neuroprotection by inhibiting distribution of active heroin metabolites to the fetal brain.

The endogenous opioid system plays an important role in brain development (McDowell and Kitchen, 1987; Sargeant et al., 2008), and prenatal exposure to exogenous opioids can disturb basic processes such as neuronal differentiation and myelination (Eschenroeder et al., 2012; Vestal-Laborde et al.,
A

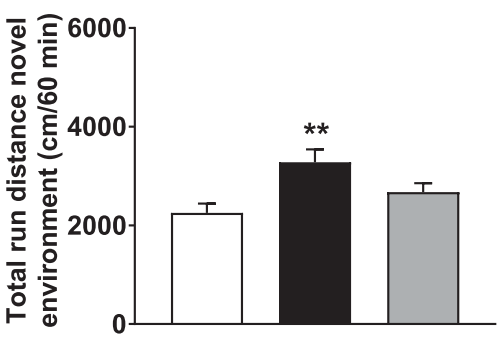

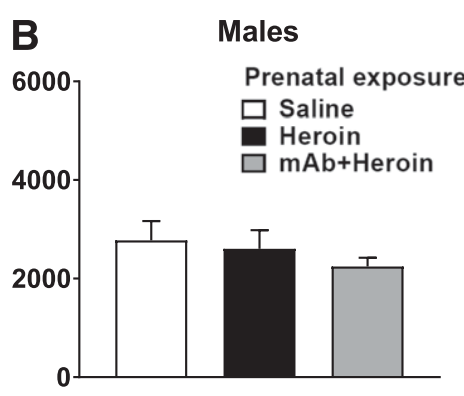

Fig. 6. Locomotor activity (cm/60 minutes) in a novel environment in adolescent (P28) females (A) and males (B) prenatally exposed to saline, heroin, or mAb + heroin. $n=8-13$. Values are mean + S.E.M., $* * P<0.01$ against saline, one-way analysis of variance with Tukey's post hoc test. 
2014; Dholakiya et al., 2016). Our findings show that female offspring exposed to heroin in utero displayed a sensitized behavioral response to heroin in adolescence. This observation correlates with other studies reporting increased rewardrelated behavior in animals prenatally exposed to different opioids (Castellano and Ammassari-Teule, 1984; Wu et al., 2009; Chiang et al., 2014; Wong et al., 2014). A sensitized drug response indicates drug-induced plasticity in the brain's reward system (Kalivas and Stewart, 1991; Robinson and Berridge, 2001) and has been linked to increased risk for subsequent drug seeking and drug taking (Vezina, 2007). mAb pretreatment to heroin-exposed pregnant mice prevented behavioral sensitization to heroin in adolescent female offspring. This demonstrates that $\mathrm{mAb}$ administration may protect the fetus against heroin-induced persistent neuroadaptations in the reward system, and possibly prevent increased vulnerability to future drug exposure in the offspring.

Prenatal opioid exposure has also been shown to induce hyperactivity upon novelty in adolescent and adult offspring (Lasky et al., 1977; Zhu and Stadlin, 2000; Timár et al., 2010; Sithisarn et al., 2017). Interestingly, a link between an animal's hyperactivity in a novel environment and a higher propensity for developing drug sensitization or drug selfadministration has been proposed for several classes of drugs, including opioids (Piazza et al., 1989; Piazza and Le Moal, 1996; Suto et al., 2001). In addition to behavioral sensitization in the adolescent females prenatally exposed to heroin, our results also revealed increased basal activity during habituation to a novel environment. This is consistent with previous findings in adolescent rats after prenatal heroin exposure (Lasky et al., 1977; Zhu and Stadlin, 2000). In the study by Zhu and Stadlin (2000), the authors proposed that the lack of habituation reflected an impaired learning mechanism, and linked their findings to similar observations in humans. Children exposed to intrauterine opioids have an increased risk of hyperactivity and $\mathrm{ADHD}$, impulsivity, and poorer learning and working memory compared with nonexposed children (Slinning, 2004; Sundelin Wahlsten and Sarman, 2013; Levine and Woodward, 2018). We found that the hyperactivity in adolescent females exposed to prenatal heroin was prevented by maternal anti-6-AM mAb pretreatment. This further indicates that passive immunization during pregnancy may protect heroin-exposed offspring against future adverse effects, such as hyperactivity or ADHD related behavior.

The present study revealed adverse long-term behavioral effects after prenatal heroin exposure in female offspring only, in accordance with the findings by Zhu and Stadlin (2000). Sex-specific effects after exposure to intrauterine opioids have been reported previously (Vathy et al., 1995; Slamberová et al., 2001; Timár et al., 2010), and may reflect the sexual dimorphism between the male and female brain from early stages of development (Hammer, 1985; Auger et al., 2001; Armoskus et al., 2014). While our findings indicate that females are more sensitive to heroin exposure during fetal development compared with males, other studies have shown morphine-induced increases in basal activity in male offspring only (Shavit et al., 1998; Timár et al., 2010). These discrepancies imply that the outcome in offspring is highly influenced by the timing of drug exposure, dosage, and/or the type of opioid drug administered during pregnancy (Byrnes and Vassoler, 2018). However, the exact underlying mechanisms for sex-characteristic effects of prenatal opioid exposure remain unidentified.

Opioid use during pregnancy has been associated with decreased birth weight, poorer birth outcomes, and withdrawal symptoms in both human and animal neonates (Farid et al., 2008; Fodor et al., 2014; Byrnes and Vassoler, 2018). In rodents, increased USV and blood levels of stress hormones are considered as animal equivalents to certain aspects of neonatal abstinence syndrome (Barr et al., 2011). We found no effects of maternal heroin exposure on maternal weight, birth weight, or litter size. Furthermore, no significant differences in USV, blood corticosterone concentrations, or $\mu$-opioid receptor binding in neonatal brain were found between the different treatment groups. Thus, our study demonstrates long-term behavioral changes induced by prenatal heroin exposure, without prominent effects observed in newborn pups. Of special concern is the finding that even very low heroin concentrations can promote persistent neurobiological changes expressed as adverse behavioral effects in the offspring.

The anti-6-AM mAb employed in our study belongs to the human IgG1 subclass, and was detected in both maternal and fetal mouse blood after administration to pregnant mice. Fetal blood mAb levels were $25 \%$ of maternal levels, suggesting that 6-AM sequestration in both maternal and fetal blood contributed to fetal neuroprotection, with the major effect occurring in the dam. In a study of active vaccination against nicotine, fetal serum antibody levels were reported to be $10 \%$ of the maternal concentration, suggesting limited transport of antibodies across the mouse placental barrier (Keyler et al., 2005). Endogenous IgG1 has been shown to cross the placental barrier by Fc receptor-mediated transport in both humans and rodents (Kim et al., 2009; Palmeira et al., 2012), and this mechanism is probably also involved in transfer of human IgGs across the mouse placenta. Upon administration of exogenous antibodies, there is a potential risk of inducing host immunogenic responses (Loisel et al., 2007; Overdijk et al., 2012). However, we have previously administered anti6-AM mAb at doses up to $100 \mathrm{mg} / \mathrm{kg}$ to adult mice without any sign of adverse immunogenic effects (Bogen et al., 2014; Kvello et al., 2016). Accordingly, we found no effect of the mAb on maternal weight gain, maternal behavior, or neonatal outcome during the 5-week experimental period of the present study, suggesting that the human IgG was tolerated by the mouse immune system.

Considering the increasing evidence of long-lasting neurocognitive consequences of prenatal opioid exposure, including opioid maintenance therapy (Farid et al., 2008), new strategies to treat pregnant opioid users are requested. A previous study comparing active and passive immunization against nicotine to prevent fetal drug exposure found passive immunization most efficient (Keyler et al., 2003), most likely due to difficulties in obtaining sufficient and controllable mAb levels upon active immunization. Administration of premade mAbs allows higher predictability of serum concentrations and reduces interindividual variation of $\mathrm{mAb}$ levels (Janda and Treweek, 2012; Zalewska-Kaszubska, 2015). The anti-6-AM $\mathrm{mAb}$ levels measured in pregnant females on E18 were approximately $50 \%$ of the expected levels based on our previous experiments in adult males (Kvello et al., 2016). This could be explained by changes in mAb pharmacokinetics during pregnancy, as shown by Hubbard et al. (2011b), who reported the half-life of a mAb against phencyclidine to be 
reduced from 6.6 days in nonpregnant rats to 3.7 and 1.4 days on E8 and E15, respectively.

Over the past decade, mAbs have evolved from being a promising theoretical treatment to clinically approved medication for a wide range of diseases, and is currently the fastest growing group of pharmaceutical molecules (Kaifu and Nakamura, 2017). The main obstacles to implement mAbs for drug abuse treatment are high-cost production of large amounts of purified IgG, and the inconvenience of repeated administrations to sustain efficient antidrug protection (Brimijoin et al., 2013). However, long-lasting mAbs with half-lives of 3 to 4 weeks make prophylactic prevention of drug abuse feasible, at least for limited time periods in patient subgroups, such as pregnant women with a history of opioid dependence. An immunotherapeutic approach to treat pregnant heroin users could be suitable for highly motivated patients (Zalewska-Kaszubska, 2015), who wish to avoid opioids during pregnancy and need a safety net against relapse.

In conclusion, we provide evidence that maternal pretreatment with a 6-AM-specific antibody protects the fetal brain from active heroin metabolites, and thereby prevents adverse long-term behavioral effects in female adolescent offspring exposed to intrauterine heroin. To our knowledge, this is the first study demonstrating immunotherapeutic protection from persistent neuronal changes induced by prenatal drug exposure. Thus, passive immunization should be further explored as potential prophylactic treatment of pregnant opioid users susceptible to heroin relapse.

\section{Acknowledgments}

We thank Affitech Research AS for making the anti-6-AM mAb available for the research and Tove Karin Herstad for excellent technical assistance with antibody production.

\section{Authorship Contributions}

Participated in research design: Kvello, Andersen, Øiestad, Aase, Mørland, Bogen.

Conducted experiments: Kvello, Andersen, Øiestad, Steinsland, Bogen.

Contributed new reagents or analytic tools: Aase.

Performed data analysis: Kvello, Steinsland, Mørland, Bogen.

Wrote or contributed to writing of the manuscript: Kvello, Andersen, Øiestad, Steinsland, Aase, Mørland, Bogen.

\section{References}

Andersen JM, Ripel A, Boix F, Normann PT, and Mørland J (2009) Increased locomotor activity induced by heroin in mice: pharmacokinetic demonstration of heroin acting as a prodrug for the mediator 6-monoacetylmorphine in vivo. $J$ Pharmacol Exp Ther 331:153-161.

Armoskus C, Moreira D, Bollinger K, Jimenez O, Taniguchi S, and Tsai HW (2014) Identification of sexually dimorphic genes in the neonatal mouse cortex and hippocampus. Brain Res 1562:23-38.

Auger AP, Perrot-Sinal TS, and McCarthy MM (2001) Excitatory versus inhibitory GABA as a divergence point in steroid-mediated sexual differentiation of the brain. Proc Natl Acad Sci USA 98:8059-8064.

Barr GA, McPhie-Lalmansingh A, Perez J, and Riley M (2011) Changing mechanisms of opiate tolerance and withdrawal during early development: animal models of the human experience. ILAR J 52:329-341.

Bhat R, Chari G, and Rao R (2006) Effects of prenatal cocaine, morphine, or both on postnatal opioid $(\mu)$ receptor development. Life Sci 78:1478-1482.

Bogen IL, Boix F, Nerem E, Mørland J, and Andersen JM (2014) A monoclonal antibody specific for 6-monoacetylmorphine reduces acute heroin effects in mice. J Pharmacol Exp Ther 349:568-576.

Bonese KF, Wainer BH, Fitch FW, Rothberg RM, and Schuster CR (1974) Changes in heroin self-administration by a rhesus monkey after morphine immunisation. Nature 252:708-710

Brimijoin S, Shen X, Orson F, and Kosten T (2013) Prospects, promise and problems on the road to effective vaccines and related therapies for substance abuse. Expert Rev Vaccines 12:323-332.

Broussard CS, Rasmussen SA, Reefhuis J, Friedman JM, Jann MW, Riehle-Colarusso T, and Honein MA; National Birth Defects Prevention Study (2011) Maternal treatment with opioid analgesics and risk for birth defects. Am J Obstet Gynecol 204:314.e1-314.e11.

Byrnes EM and Vassoler FM (2018) Modeling prenatal opioid exposure in animals: current findings and future directions. Front Neuroendocrinol 51:1-13.

Castellano C and Ammassari-Teule M (1984) Prenatal exposure to morphine in mice: enhanced responsiveness to morphine and stress. Pharmacol Biochem Behav 21: 103-108.

Chiang YC, Hung TW, and Ho IK (2014) Development of sensitization to methamphetamine in offspring prenatally exposed to morphine, methadone and buprenorphine. Addict Biol 19:676-686.

Dholakiya SL, Aliberti A, and Barile FA (2016) Morphine sulfate concomitantly decreases neuronal differentiation and opioid receptor expression in mouse embryonic stem cells. Toxicol Lett 247:45-55.

Eschenroeder AC, Vestal-Laborde AA, Sanchez ES, Robinson SE, and Sato-Bigbee C (2012) Oligodendrocyte responses to buprenorphine uncover novel and opposing roles of $\mu$-opioid- and nociceptin/orphanin FQ receptors in cell development: implications for drug addiction treatment during pregnancy. Glia 60:125-136.

Farid WO, Dunlop SA, Tait RJ, and Hulse GK (2008) The effects of maternally administered methadone, buprenorphine and naltrexone on offspring: review of human and animal data. Curr Neuropharmacol 6:125-150.

Fodor A, Tímár J, and Zelena D (2014) Behavioral effects of perinatal opioid exposure. Life Sci 104:1-8.

Fyffe J and Dutton GJ (1975) Induction of UDPglucose dehydrogenase during development, organ culture, and exposure to phenobarbital. Its relation to levels of UDPglucuronic acid and overall glucuronidation in chicken and mouse. Biochim Biophys Acta 411:41-49.

Gagin R, Kook N, Cohen E, and Shavit Y (1997) Prenatal morphine enhances morphine-conditioned place preference in adult rats. Pharmacol Biochem Behav 58:525-528.

Hammer RP, Jr (1985) The sex hormone-dependent development of opiate receptors in the rat medial preoptic area. Brain Res 360:65-74.

Hartvig P, Lindberg BS, Lilja A, Lundqvist H, Långström B, and Rane A (1989) Positron emission tomography in studies on fetomaternal disposition of opioids. Dev Pharmacol Ther 12:74-80.

Hickey JE, Suess PE, Newlin DB, Spurgeon L, and Porges SW (1995) Vagal tone regulation during sustained attention in boys exposed to opiates in utero. Addict Behav 20:43-59.

Hubbard JJ, Laurenzana EM, Williams DK, Gentry WB, and Owens SM (2011a) Chronic anti-phencyclidine monoclonal antibody therapy decreases phencyclidineinduced in utero fetal mortality in pregnant rats. Int Immunopharmacol 11: 2181-2187.

Hubbard JJ, Laurenzana EM, Williams DK, Gentry WB, and Owens SM (2011b) The fate and function of therapeutic antiaddiction monoclonal antibodies across the reproductive cycle of rats. J Pharmacol Exp Ther 336:414-422.

Janda KD and Treweek JB (2012) Vaccines targeting drugs of abuse: is the glass halfempty or half-full? Nat Rev Immunol 12:67-72.

Kaifu T and Nakamura A (2017) Polymorphisms of immunoglobulin receptors and the effects on clinical outcome in cancer immunotherapy and other immune diseases: a general review. Int Immunol 29:319-325.

Kalivas PW and Stewart J (1991) Dopamine transmission in the initiation and expression of drug- and stress-induced sensitization of motor activity. Brain Res Brain Res Rev 16:223-244

Karinen R, Andersen JM, Ripel A, Hasvold I, Hopen AB, Mørland J, and Christophersen AS (2009) Determination of heroin and its main metabolites in small sample volumes of whole blood and brain tissue by reversed-phase liquid chromatography-tandem mass spectrometry. J Anal Toxicol 33:345-350.

Keyler DE, Dufek MB, Calvin AD, Bramwell TJ, LeSage MG, Raphael DE, Ross CA Le CT, and Pentel PR (2005) Reduced nicotine distribution from mother to fetal brain in rats vaccinated against nicotine: time course and influence of nicotine dosing regimen. Biochem Pharmacol 69:1385-1395.

Keyler DE, Shoeman D, LeSage MG, Calvin AD, and Pentel PR (2003) Materna vaccination against nicotine reduces nicotine distribution to fetal brain in rats. $J$ Pharmacol Exp Ther 305:587-592.

Killian A, Bonese K, Rothberg RM, Wainer BH, and Schuster CR (1978) Effects of passive immunization against morphine on heroin self-administration. Pharmacol Biochem Behav 9:347-352.

Kim J, Mohanty S, Ganesan LP, Hua K, Jarjoura D, Hayton WL, Robinson JM, and Anderson CL (2009) FcRn in the yolk sac endoderm of mouse is required for IgG transport to fetus. J Immunol 182:2583-2589.

Kvello AM, Andersen JM, Øiestad EL, Mørland J, and Bogen IL (2016) Pharmacological effects of a monoclonal antibody against 6-monoacetylmorphine upon heroin-induced locomotor activity and pharmacokinetics in mice. J Pharmacol Exp Ther 358:181-189.

Lasky DI, Zagon IS, and McLaughlin PJ (1977) Effect of maternally administered heroin on the motor activity of rat offspring. Pharmacol Biochem Behav 7:281-284.

Levine TA and Woodward LJ (2018) Early inhibitory control and working memory abilities of children prenatally exposed to methadone. Early Hum Dev 116:68-75. Loisel S, Ohresser M, Pallardy M, Daydé D, Berthou C, Cartron G, and Watier H (2007) Relevance, advantages and limitations of animal models used in the development of monoclonal antibodies for cancer treatment. Crit Rev Oncol Hematol 62:34-42.

Lowry OH, Rosebrough NJ, Farr AL, and Randall RJ (1951) Protein measurement with the Folin phenol reagent. J Biol Chem 193:265-275.

Lu R, Liu X, Long H, and Ma L (2012) Effects of prenatal cocaine and heroin exposure on neuronal dendrite morphogenesis and spatial recognition memory in mice. Neurosci Lett 522:128-133.

McDowell J and Kitchen I (1987) Development of opioid systems: peptides, receptors and pharmacology. Brain Res 434:397-421.

McQueen K and Murphy-Oikonen J (2016) Neonatal abstinence syndrome. N Engl J Med 375:2468-2479. 
Minozzi S, Amato L, Bellisario C, Ferri M, and Davoli M (2013) Maintenance agonist treatments for opiate-dependent pregnant women. Cochrane Database Syst Rev 12: CD006318.

Moghaddam A, Borgen T, Stacy J, Kausmally L, Simonsen B, Marvik OJ, Brekke $\mathrm{OH}$, and Braunagel $\mathrm{M}$ (2003) Identification of $\mathrm{scFv}$ antibody fragments that specifically recognise the heroin metabolite 6 -monoacetylmorphine but not morphine. $J$ Immunol Methods 280:139-155.

Neal BS and Sparber SB (1986) Mianserin attenuates naloxone-precipitated withdrawal signs in rats acutely or chronically dependent upon morphine. J Pharmacol Exp Ther 236:157-165.

Ornoy A, Michailevskaya V, Lukashov I, Bar-Hamburger R, and Harel S (1996) The developmental outcome of children born to heroin-dependent mothers, raised at home or adopted. Child Abuse Negl 20:385-396.

Ornoy A, Segal J, Bar-Hamburger R, and Greenbaum C (2001) Developmental outcome of school-age children born to mothers with heroin dependency: importance of environmental factors. Dev Med Child Neurol 43:668-675.

Overdijk MB, Verploegen S, Ortiz Buijsse A, Vink T, Leusen JH, Bleeker WK, and Parren PW (2012) Crosstalk between human IgG isotypes and murine effector cells. J Immunol 189:3430-3438.

Palmeira P, Quinello C, Silveira-Lessa AL, Zago CA, and Carneiro-Sampaio M (2012) IgG placental transfer in healthy and pathological pregnancies. Clin Dev Immunol 2012:985646.

Piazza PV, Deminière JM, Le Moal M, and Simon H (1989) Factors that predict individual vulnerability to amphetamine self-administration. Science $\mathbf{2 4 5}$ 1511-1513.

Piazza PV and Le Moal ML (1996) Pathophysiological basis of vulnerability to drug abuse: role of an interaction between stress, glucocorticoids, and dopaminergic neurons. Annu Rev Pharmacol Toxicol 36:359-378.

Pichini S, Puig C, Zuccaro P, Marchei E, Pellegrini M, Murillo J, Vall O, Pacifici R, and García-Algar O (2005) Assessment of exposure to opiates and cocaine during pregnancy in a Mediterranean city: preliminary results of the "Meconium Project". Forensic Sci Int 153:59-65.

Pravetoni M, Raleigh MD, Le Naour M, Tucker AM, Harmon TM, Jones JM, Birnbaum AK, Portoghese PS, and Pentel PR (2012) Co-administration of morphine and oxycodone vaccines reduces the distribution of 6-monoacetylmorphine and oxycodone to brain in rats. Vaccine 30:4617-4624.

Raleigh MD, Pentel PR, and LeSage MG (2014) Pharmacokinetic correlates of the effects of a heroin vaccine on heroin self-administration in rats. PLoS One 9: e115696.

Robinson TE and Berridge KC (2001) Incentive-sensitization and addiction. Addiction 96:103-114.

Sargeant TJ, Miller JH, and Day DJ (2008) Opioidergic regulation of astroglial/neuronal proliferation: where are we now? $J$ Neurochem 107:883-897.

Shavit Y, Cohen E, Gagin R, Avitsur R, Pollak Y, Chaikin G, Wolf G, and Yirmiya R (1998) Effects of prenatal morphine exposure on NK cytotoxicity and responsiveness to LPS in rats. Pharmacol Biochem Behav 59:835-841.

Sithisarn T, Legan SJ, Westgate PM, Wilson M, Wellmann K, Bada HS, and Barron $\mathrm{S}$ (2017) The effects of perinatal oxycodone exposure on behavioral outcome in a rodent model. Front Pediatr 5:180.

Slamberová R, Schindler CJ, Pometlová M, Urkuti C, Purow-Sokol JA, and Vathy I (2001) Prenatal morphine exposure differentially alters learning and memory in male and female rats. Physiol Behav 73:93-103.

Slinning K (2004) Foster placed children prenatally exposed to poly-substances-attention-related problems at ages 2 and 4 1/2. Eur Child Adolesc Psychiatry 13 $19-27$

Stowe GN, Schlosburg JE, Vendruscolo LF, Edwards S, Misra KK, Schulteis G, Zakhari JS, Koob GF, and Janda KD (2011) Developing a vaccine against multiple psychoactive targets: a case study of heroin. CNS Neurol Disord Drug Targets 10: 865-875.
Sulima A, Jalah R, Antoline JFG, Torres OB, Imler GH, Deschamps JR, Beck Z, Alving CR, Jacobson AE, Rice KC, et al. (2018) A stable heroin analogue that can serve as a vaccine hapten to induce antibodies that block the effects of heroin and its metabolites in rodents and that cross-react immunologically with related drugs of abuse. J Med Chem 61:329-343.

Sundelin Wahlsten V and Sarman I (2013) Neurobehavioural development of preschool-age children born to addicted mothers given opiate maintenance treatment with buprenorphine during pregnancy. Acta Paediatr 102:544-549.

Suto N, Austin JD, and Vezina P (2001) Locomotor response to novelty predicts a rat's propensity to self-administer nicotine. Psychopharmacology (Berl) 158 $175-180$.

Tempel A, Habas J, Paredes W, and Barr GA (1988) Morphine-induced downregulation of mu-opioid receptors in neonatal rat brain. Brain Res 469:129-133.

Terplan M (2017) Women and the opioid crisis: historical context and public health solutions. Fertil Steril 108:195-199.

Timár J, Sobor M, Király KP, Gyarmati S, Riba P, Al-Khrasani M, and Fürst S (2010) Peri, pre and postnatal morphine exposure: exposure-induced effects and sex differences in the behavioural consequences in rat offspring. Behav Pharmacol 21 $58-68$

Umans JG and Inturrisi CE (1981) Pharmacodynamics of subcutaneously administered diacetylmorphine, 6-acetylmorphine and morphine in mice. J Pharmacol Exp Ther 218:409-415.

Vathy I, Rimanoczy A, Eaton RC, and Katay L (1995) Sex dimorphic alterations in postnatal brain catecholamines after gestational morphine. Brain Res Bull 36: $185-193$.

Vestal-Laborde AA, Eschenroeder AC, Bigbee JW, Robinson SE, and Sato-Bigbee C (2014) The opioid system and brain development: effects of methadone on the oligodendrocyte lineage and the early stages of myelination. Dev Neurosci 36:409-421.

Vezina P (2007) Sensitization, drug addiction and psychopathology in animals and humans. Prog Neuropsychopharmacol Biol Psychiatry 31:1553-1555.

Wang Y and Han TZ (2009) Prenatal exposure to heroin in mice elicits memory deficits that can be attributed to neuronal apoptosis. Neuroscience 160:330-338.

White JM and Lopatko OV (2007) Opioid maintenance: a comparative review of pharmacological strategies. Expert Opin Pharmacother 8:1-11.

White SJ, Hendrickson HP, Atchley WT, Laurenzana EM, Gentry WB, Williams DK, and Owens SM (2014) Treatment with a monoclonal antibody against methamphetamine and amphetamine reduces maternal and fetal rat brain concentrations in late pregnancy. Drug Metab Dispos 42:1285-1291.

Wong CS, Lee YJ, Chiang YC, Fan LW, Ho IK, and Tien LT (2014) Effect of prenatal methadone on reinstated behavioral sensitization induced by methamphetamine in adolescent rats. Behav Brain Res 258:160-165.

Wu LY, Chen JF, Tao PL, and Huang EY (2009) Attenuation by dextromethorphan on the higher liability to morphine-induced reward, caused by prenatal exposure of morphine in rat offspring. J Biomed Sci 16:106.

Yanai J, Huleihel R, Izrael M, Metsuyanim S, Shahak H, Vatury O, and Yaniv SP (2003) Functional changes after prenatal opiate exposure related to opiate receptors' regulated alterations in cholinergic innervation. Int $J$ Neuropsychopharmaco 6:253-265.

Zalewska-Kaszubska J (2015) Is immunotherapy an opportunity for effective treatment of drug addiction? Vaccine 33:6545-6551.

Zhu JH and Stadlin A (2000) Prenatal heroin exposure. Effects on development, acoustic startle response, and locomotion in weanling rats. Neurotoxicol Teratol 22: 193-203.

Address correspondence to: Inger Lise Bogen, Section for Drug Abuse Research, Oslo University Hospital, P.O. Box 4950 Nydalen, N-0424 Oslo, Norway. E-mail: inger.lise.bogen@ous-hf.no 